\title{
Steroids: A Timeless Fascination
}

Cholesterol and its Bio-products

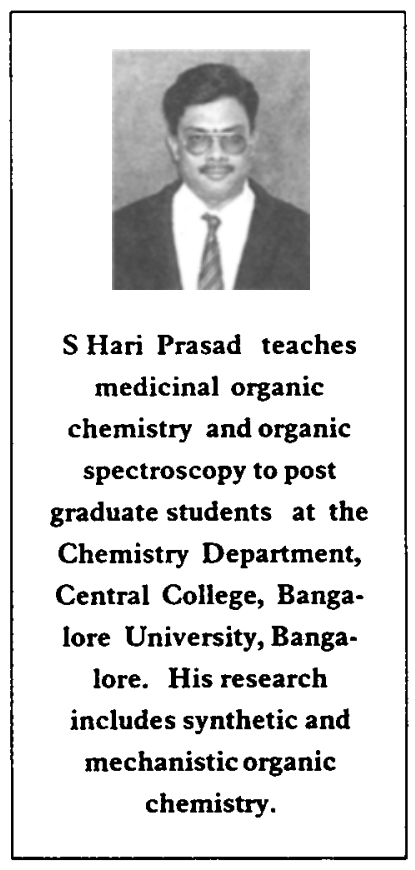

Keywords

Cholesterol, bio-products, bile acids, corticosteroids, sex hormones.

\section{S Hari Prasad}

Steroids are solid organic compounds derived from all life forms, including microorganisms, plants and animals. They obtain their generic name 'steroids' from Greek: stereos = solid. Steroids encompass a wide variety of compounds of vital importance to life such as sterols, bile acids, sex hormones, anti-inflammatory corticoid hormones, etc. This article highlights some of the important aspects of cholesterol, the principal sterol of higher animals.

Cholesterol is a molecule that has fascinated scientists and commonman alike. Thirteen Nobel Prizes have been awarded to scientists who have devoted major parts of their careers towards its study.

Cholesterol, the first steroid to be isolated, was discovered by Michel Eugene Chevreul in 1812. Chevreul isolated cholesterol from the non-saponifiable portion of animal lipids. Cholesterol is a $\mathrm{C}_{27}$ alcohol. It is the principal sterol of higher animals. An average human weighing $80 \mathrm{~kg}$ contains approximately $250 \mathrm{~g}$ of cholesterol. Cholesterol is an essential constituent of lipid membranes. It is widely distributed in all body tissues, especially in the brain and spinal cord. It is also present in animal fats or oils.

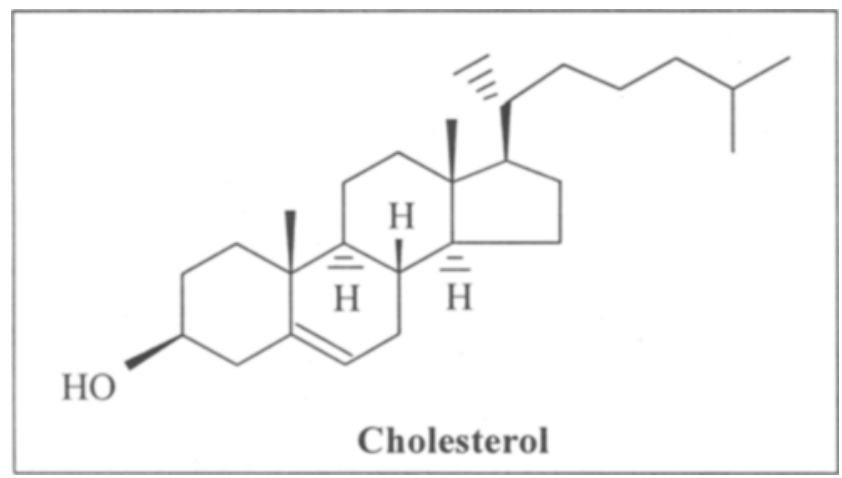


The predominant constituent of human gall stones is cholesterol.

Cholesterol is primarily synthesized in the liver, from which it is secreted as a lipoprotein constituent. Lipoproteins are large assemblies of lipids in association with proteins. The two most important classes of lipoproteins are high density lipoprotein (HDL) and low density lipoprotein (LDL). When cholesterol is associated with high density lipoprotein (HDL), it is called good cholesterol. HDL is responsible for the formation of a wide variety of other important bioactive steroids. However, when associated with low density lipoprotein (LDL), it is called bad cholesterol. LDL leads to the formation of blood clots, the chief causative agent of heart attacks and strokes. Deposition of LDL on the walls of arteries leads to atherosclerosis, characterized by the hardening of the arterial walls and thrombosis. Atherosclerotic plaques have been found in excavated Egyptian mummies, indicating the prevalence of chronic heart disease even in ancient times. Blood cholesterol levels are a good statistical indicator of the potential risk of a heart attack. Cholesterol levels in the blood maybe reduced by using a new class of drugs: The statins which are inhibitors of the enzyme hydroxymethylglutarylcoenzyme-A reductase which is.responsible for the production of the body's natural cholesterol.

The percentage composition and size of LDL and HDL are given in Table 1.

Even though cholesterol is found to have no biological activity, it is an important precursor the bile acids, corticosteroids, sex hormones, etc.
Lipoproteins are large assemblies of lipids in association with proteins. The two most important classes of lipoproteins are high density lipoprotein (HDL) and low density lipoprotein (LDL).

\begin{tabular}{|lllllll|}
\hline Name & $\begin{array}{l}\text { Synthesized } \\
\text { in }\end{array}$ & $\begin{array}{l}\text { Size } \\
(\mathrm{nm})\end{array}$ & $\begin{array}{l}\text { Protein } \\
(\%)\end{array}$ & $\begin{array}{l}\text { Phospholipids } \\
(\%)\end{array}$ & $\begin{array}{l}\text { Cholesterol } \\
(\%)\end{array}$ & $\begin{array}{l}\text { Triglyceride } \\
(\%)\end{array}$ \\
\hline $\begin{array}{l}\text { LDL or } \\
\beta \text {-lipoprotein }\end{array}$ & Blood and liver & $15-25$ & 20 & 24 & 45 & 10 \\
$\begin{array}{l}\text { HDL or } \\
\alpha \text {-lipoprotein }\end{array}$ & Liver & $7-10$ & 50 & 30 & 15 & 5 \\
\hline
\end{tabular}




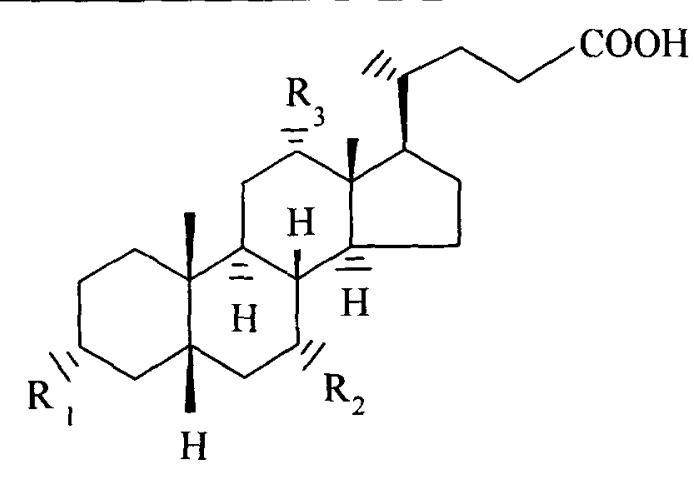

\section{Bile Acids}

$\mathrm{R}_{1}=\mathrm{OH} ; \mathrm{R}_{2}=\mathrm{R}_{3}=\mathrm{H}$ : Lithocholic acid

$\mathrm{R}_{1}=\mathrm{R}_{3}=\mathrm{OH} ; \mathrm{R}_{2}=\mathrm{H}$ : Desoxycholic acid

$\mathrm{R}_{1}=\mathrm{R}_{2}=\mathrm{R}_{3}=\mathrm{OH}:$ Cholic acid

$\mathrm{R}_{1}=\mathrm{R}_{2}=-\mathrm{OH} ; \mathrm{R}_{3}=\mathrm{H}$ : Ursodesoxycholic acid

$\mathrm{R}_{1}=\mathrm{R}_{2}=\mathrm{OH} ; \mathrm{R}_{3}=\mathrm{H}$ : Chenodesoxycholic acid

$\mathrm{R}_{1}=\mathrm{R}_{2}=\mathrm{R}_{3}=\mathrm{H}$ : Cholanic acid

\section{Bile Acids}

Human bile is a golden yellow alkaline liquid. It is produced in the liver and stored in the gall bladder. Small amounts of bile are regularly secreted into the intestines. Bile acids are the chief constituents of the solid matter of bile. Bile acids are $\mathrm{C}_{24}$ steroids. Leopold Gmelin in 1828 isolated an impure preparation of cholic acid (Gk: chole $=$ bile) from the non-saponifiable part of ox-bile. Hans Fischer in 1911 isolated another hard stone-like acid from gall stones which he aptly named as lithocholic acid (Gk:lithos = stone). Wieland reported the isolation of desoxycholic acid in 1912.

Bile acids are formed from cholesterol after a series of complex biochemical reactions, which bring about changes in the number of the hydroxyl groups, their configuration, and the ring conformations. Bile acids are found in bile juice as sodium salts of glycine or taurine. Due to the non-polar steroidal nucleus and polar carboxylic acid side chain, bile acids act as detergents and help in emulsifying fats and digestion of food. Approximately twenty different bile acids are known. Bile acids are important today as starting materials for the semi-synthesis of other medicinal steroids. Chenodesoxycholic acid and ursodesoxycholic acid are used to dissolve cholesterol gallstones as an alternative to surgery. Dehydrocholic acid is used after surgery to improve bilary drainage.

\section{Corticosteroids and Sex Hormones}

Cholesterol also undergoes a series of biosynthetic degradations to form a variety of hormones. Some of the important steroidal 
hormones derived from cholesterol are the corticosteroids and the sex hormones.

Corticosteroids are $\mathrm{C}_{21}$ units found in the cortex of the adrenal gland. The important corticosteroids are cortisol, cortisone and aldosterone. Corticosteroids play an important role as antiinflammatory and anti-allergic agents.

Female sex hormones are broadly classified into two groups: the gestogens and the oestrogens. Progesterone is a $\mathrm{C}_{21}$ gestogen which regulates the female reproductive cycle. Oestradiol and oestrone are $\mathrm{C}_{18}$ oestrogens. These oestrogens govern primary female characteristics.

The male sex hormones termed androgens include the $\mathrm{C}_{19}$ units testosterone and dehydroepiandrosterone. Androgens are responsible for primary male characteristics.

The levels of these hormones are controlled by certain polypeptides/glycoproteins produced by the pituitary gland. Corticosteroids are controlled by corticotrophin (adrenocorticotrophic

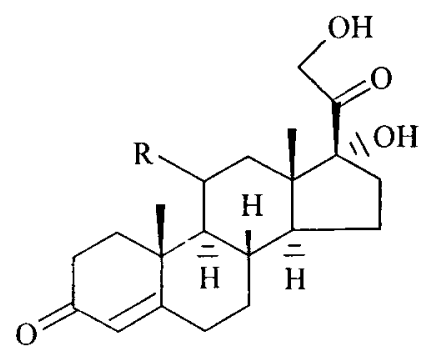

cortisol R: $-\mathrm{OH}$

cortisone $R: C=0$

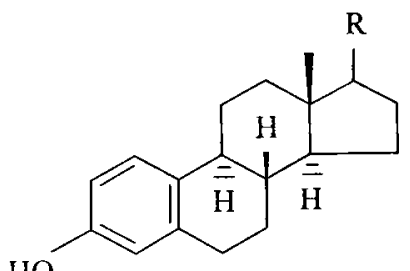

$\mathrm{HO}$

oestradiol R: $-\mathrm{OH}$ oestrone R: $\mathrm{C}=\mathrm{O}$

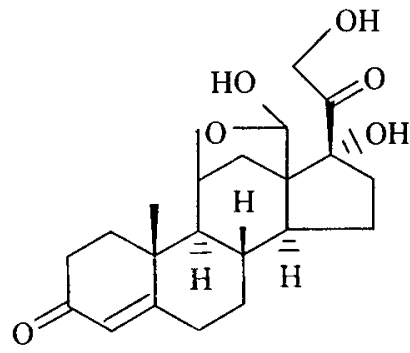

aldosterone

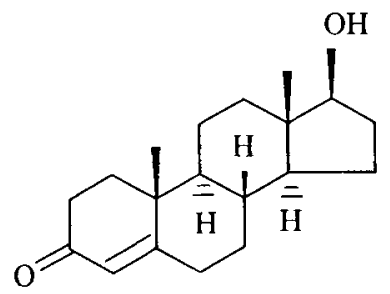

testosterone<smiles>CC(=O)[C@H]1CC[C@H]2[C@@H]3CCC4=CC(=O)CC[C@]4(C)[C@H]3CC[C@]12C</smiles>

progesterone

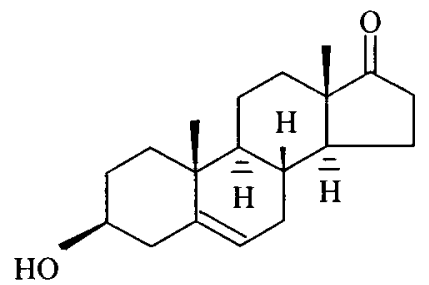

dehydroepiandrosterone 


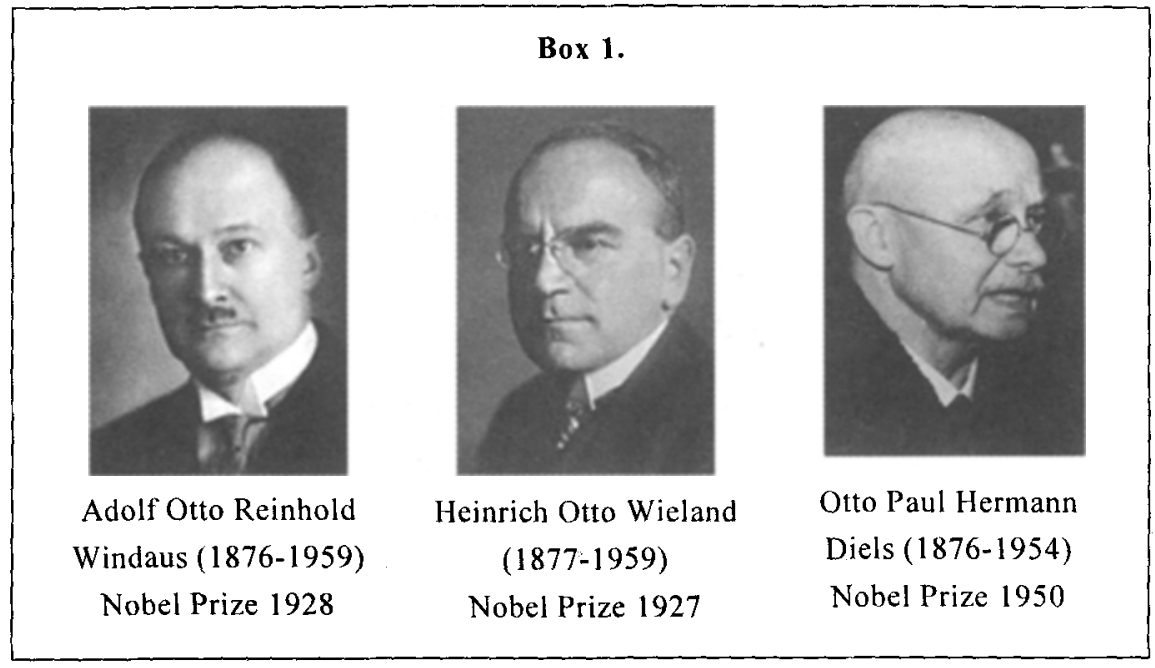

* Dedicated to Prof K M Sivanandiah, former Principal, Central College, Bangalore University, Bangalore, on the occasion of his 73rd birthday. The author thanks the UGC and DST for financial assistance.

Address for Correspondence $S$ Hari Prasad Department of Chemistry Central College Campus Bangalore University Bangalore 560001 , India. Emait: hariprasad@mycatsindia.com hormone, ACTH), a straight chain polypeptide of 39 amino acid residues. The levels of the sex hormones are controlled by the glycoprotein gonadotrophins: luteinising hormone (LH) and follicle-stimulating hormone (FSH) of 204 and 210 amino acid residues respectively.

Three eminent chemists who pioneered steroidal chemistry at the turn of the twentieth century were Windaus, Wieland and Diels (Box 1). Windaus was primarily responsible for the initial studies of cholesterol. Wieland gave the structural elucidation of bile acids and finally the structure of steroids itself as depicted today. Diels among other studies contributed to the finalization of the structure of steroids as derivatives of perhydro-cyclopentanophenanthrene in addition to giving a good method to construct six membered cyclic compounds by the well-known DielsAlder reaction.

\section{Suggested Reading}

[1] http://www.chem.qmul.ac.uk/iupac/steroid/

[2] http://www.nobel.se/chemistry/laureates/1927/wieland biohtml

[3] http:/www.nobel.se/chemistry/laureates/1928/windaus-biohtml

[4] http://www.nobel.se/chemistry/laureates/1950/diels-biohtml 